\title{
POLITITIKK

\section{Evig aktivisme i uendelig krig: sikkerhed, status og strategisk kultur i dansk udenrigspolitik}

\author{
Anders Wivel \\ Københavns Universitet, Danmark
}

\begin{abstract}
Sammendrag
Danmark har i årene siden den kolde krigs afslutning udviklet sig til at være en permanent krigsførende nation. Den militære aktivisme er karakteriseret ved meget forskellige typer af engagementer, både hvad angår antallet af udsendte og deres mandat, indlejring $\mathrm{i}$ forskellige internationale organisationer og koalitioner, og udsendelser til forskellige dele af verden. Den danske vilje til aktivt at fastholde en status som bidragende og konstruktiv allieret gennem deltagelse $i$ internationale operationer er drevet af en opfattelse af USA som afgørende for Danmarks nationale sikkerhed og understøttet af en aktivistisk og pragmatisk strategisk kultur. Den militære aktivisme er på den baggrund robust. Samtidig er der tegn på forandring i finansiering, geografisk fokus og valg af samarbejdspartnere.
\end{abstract}

Nøgleord: Dansk udenrigspolitik • aktivisme $\bullet$ status $\bullet$ strategisk kultur • USA

\footnotetext{
^Kontaktinformasjon: Anders Wivel, e-post: aw@ifs.ku.dk

(C)2020 Anders Wivel. This is an Open Access article distributed under the terms of the Creative Commons Attribution 4.0 International License (http://creativecommons.org/licenses/by/4.0/), allowing third parties to copy and redistribute the material in any medium or format and to remix, transform, and build upon the material for any purpose, even commercially, provided the original work is properly cited and states its license.

Citation: Wivel, A. (2020). Evig aktivisme $i$ uendelig krig: sikkerhed, status og strategisk kultur $i$ dansk udenrigspolitik. Internasjonal Politikk, 78(3), 411-420. http://dx.doi.org/10.23865/intpol.v78.2536
} 


\section{Introduktion $^{\mathrm{I}}$}

Danmark har siden den kolde krigs afslutning bidraget til mere end 80 militære operationer. Forsvaret har i perioden foretaget ca. 80.000 udsendelser, primært i regi af FN, NATO og koalitioner af villige lande (Forsvarsministeriet, 2020). Danske soldater har været udsendt i Europa, Mellemøsten, Afrika, Asien samt til den amerikanske centralkommando CENTCOM i Florida. Udsendelserne har meget forskellig karakter og spænder over eksempelvis rådgivere til kapacitetsopbygning $\mathrm{i}$ Østafrika og forsvarsreformer i Ukraine, troppetransport i Mali, transport af kemiske våben væk fra Syrien, træning af sikkerhedsstyrker i Irak og soldater i Ukraine, bidrag til NATO's multinationale styrke i Estland og overvågning af det islandske luftrum, luftbombardementer af Libyen samt krigsdeltagelse i Irak og Afghanistan og på Balkan med tusindvis af soldater.

Denne bredspektrede militære aktivisme - "anvendelse af det militære instrument til internationale aktiviteter, der rækker udover selvforsvar" (Jakobsen, 2015, s. 6) - har gjort Danmark til "en af verdens største troppebidragydere målt pr. indbygger" (Jakobsen, 2019, s. 139). Den har præget dansk udenrigspolitik i en grad, så der i dag ofte sættes lighedstegn mellem den militære aktivisme og dansk udenrigspolitisk aktivisme generelt, selv om aktivismen omfatter både nordiske, europapolitiske og udviklingspolitiske aspekter (Pedersen \& Ringsmose, 2017, s. 339-340). Den militære aktivisme er blevet hverdag i Danmark, selv om krigene føres langt borte, debatten om dens formål og konsekvenser er begrænset, og kritikken med få undtagelser er ikke-eksisterende. Danmark er aktiv bidragyder til en "uendelig krig" (Breitenbauch, 2015), hvor Danmarks udbud af militært engagement afspejler de politiske beslutningstageres vilje til at imødekomme efterspørgslen fra vores allierede og samarbejdspartnere, ikke mindst USA. "Der er ikke tale om direkte pres fra USA med trusler om sanktioner eller løfte om gevinster, men forsøg fra danske beslutningstagere på at imødekomme amerikanske præferencer" (Mariager \& Wivel, 2019, s. 22). Artiklen redegør for den historiske baggrund, diskuterer de aktuelle årsager til Danmarks valg af militær aktivisme og vurderer, hvorvidt politikken vil være robust i fremtiden.

\section{To historiske megatrends: Fra stormagt til småstat, fra neutral til kerneallieret}

Danmarks militære aktivisme tager sit udgangspunkt $i$ to historiske udviklinger med betydning for både det udenrigspolitiske handlerum og den strategiske kultur.

Fra baltisk stormagt til nordisk småstat

Danmarks tidlige udenrigspolitiske historie er historien om et land i krig. Forsvarsværket Dannevirke blev opført i begyndelsen af 800-tallet af Kong Gudfred, der lå

${ }^{1} \mathrm{Jeg}$ vil gerne takke to anonyme reviewers samt temaredaktørerne for nyttige kommentarer i forbindelse med udarbejdelse af artiklen. 
i krig med Frankerrigets kejser Karl den Store om herredømmet over handelsvejen fra Nordsøen til Østersøen. Da Danmarks territorium og styre i 900- og 1000-tallet fik en større grad af kontinuitet, var det med vikingekongen Harald Blåtands erobring af Danmark og Norge og siden med Knud den Stores samling af Danmark, Norge, England og dele af Sverige under den danske krone (Albrechtsen, Frandsen \& Lind, 2006, s. 28-42). Krig og militær magt var afgørende forudsætninger for Danmarks opbygning af et Østersøimperium i slutningen af 1300-tallet og begyndelsen af 1400-tallet, og en stærk flåde og hær medvirkede til at fastholde landets status som Nordens førende magt frem til begyndelsen af 1600-tallet. Krig var "et legitimt middel i den dynastiske politik, og militæret spillede en central rolle i statshierarkiet" (Heurlin, 2007, s. 19).

Mens de første århundreder af Danmarkshistorien er historien om en regional stormagt, der dominerede Norden og Østersøområdet gennem sin militære magt, så var Danmarks krigsdeltagelse fra 1600-tallet og frem til 1864 en nederlagshistorie. I Trediveårskrigen havde den danske konges nederlag til den tysk-romerske kejser svækket Danmark i en række efterfølgende konflikter med Sverige. I slutningen af 1700 -tallet havde Danmark forsøgt at udnytte en væbnet neutralitet til økonomisk fordel, men derved udfordret det britiske søherredømme. I 1801 sænkede briterne en stor del af den dansk-norske flåde, og i 1807 blev størstedelen af den tilbageværende flåde britisk krigsbytte. I 1814 tabte Danmark Norge som følge af en alliance med det tabende Frankrig i de sidste år af Napoleonskrigene. I 1864 tabte Danmark de tre fyrstendømmer Slesvig, Holsten og Lauenborg i et nederlag til Prøjsen og Østrig, og Danmarks territorium blev reduceret med en tredjedel. Nederlaget blev et vendepunkt i dansk udenrigspolitik. Både danske og udenlandske beslutningstagere betragtede nu Danmark som en småstat. Det var konklusionen på den gradvise "territorielle krympning af riget”, der var pågået siden 1600-tallet (Petersen, 2005, s. 52), og som siden har fungeret som udgangspunkt for dansk udenrigspolitik. Danmark var nu en småstat: ude af stand til at forsvare sig selv og afhængig af stormagternes magtspil.

Fra neutral til kerneallieret

1864 er "Stunde Null" i dansk udenrigspolitik (Glenthøj, 2018). Den danske stat var ikke længere en militært funderet organisation med internationale forpligtelser og ambitioner, men en tilpasningsvillig småstat med fokus på forsvar af befolkningens suverænitet og den territorielle integritet (Heurlin, 2007, s. 19). Med udgangspunkt i dogmer som "hvad udad tabes skal indad vindes" (om landets økonomiske og identitetspolitiske genopbygning efter 1864) og "hvad skal det nytte" (om småstatens behov for at satse på diplomati fremfor militær oprustning), forfulgte Danmark frem til Anden Verdenskrig en neutralitetsbaseret "ligge død"-politik, der efterlod landet stort set forsvarsløst, da krigen brød ud. Politikken formåede ikke at holde Danmark ude af krigen, og løsningen efter fem års besættelse blev en genopbygning af Forsvaret med bred politisk opbakning fra en koalition af centrum-højre og centrum-venstre partier. I første omgang forsøgte man en fortsættelse af neutralitetspolitikken og 
afsøgte mulighederne for et skandinavisk forsvarsforbund med Sverige og Norge, men manglende opbakning fra USA fik i 1949 Danmark til at til at tilslutte sig Atlantpagten og dermed NATO.

NATO-medlemskabet blev i Danmark ikke set som et forsvar for et vestligt værdifællesskab, men snarere som en nødvendig forsikringspræmie (Ringsmose, 2009). Danmark var "allieret med forbehold" (Villaume, 1995) eller ligefrem "quasi-neutral" (Holbraad, 1991) og fulgte Norges eksempel med en afvisning af udenlandske militære baser og kernevåben på dansk territorium med undtagelse af Grønland, der blev brugt til at kompensere for den generelle danske alliancepolitik. Det danske forsvarsbudget lå i det meste af den kolde krig på mellem to og tre procent af BNP og kom efter 1963 aldrig over tre procent (SIPRI, 2019). Bortset fra det danske bidrag til den britiske besættelseszone i Tyskland efter Anden Verdenskrig havde samtlige danske udsendelser af Forsvarets personel direkte mandat fra FN, og fokus var udelukkende på observation eller fredsbevarelse.

Sovjetunionens kollaps i 1991 betød, at Danmark nu for første gang i landets historie var omgivet af venligsindede stater (Petersen, 2006, s. 427). Danmark valgte at udnytte det større udenrigspolitiske handlerum til at efterkomme den betydelige stigning i den internationale efterspørgsel efter bidrag til internationale operationer. Alene i 1990'erne bidrog forsvarets personel til 30 internationale operationer (mod 13 i hele perioden 1945-1989) og 20-25 operationer i hvert af de følgende årtier (Mariager \& Wivel, 2019, 136). Med undtagelse af deltagelse i invasionen af Irak i 2003 blev udviklingen båret af bred politisk opbakning fra de regeringsbærende partier fra centrum-højre og centrum-venstre. I 1999 deltog Danmark for første gang $\mathrm{i}$ en militær operation uden direkte $\mathrm{FN}$-mandat i forbindelse med Operation Allied Force i Kosovo, og i 2004 opgav Danmark territorialforsvaret til fordel for en mindre styrke, der hurtigt og fleksibelt ville kunne insættes i forbindelse med militære operationer rundt omkring i verden. De danske tropper deltog nu aktivt i at skabe fred, stabilisere samfund og beskytte civilbefolkninger, men ikke altid med et direkte FN-mandat og med vekslende succes. NATO blev den primære organisation for Danmarks militære aktivisme fra slutningen af 1990'erne og frem. Danmark var blevet en "upåklagelig allieret" (Ringsmose \& Rynning, 2008) eller måske ligefrem en "super-Atlanticist" (Mouritzen, 2007).

\section{Sikkerhed, status og strategisk kultur i Danmarks militære aktivisme}

Spørgsmålet bliver på den baggrund, hvorfor en lille nordisk velfærdsstat som Danmark valgte at udnytte det større udenrigspolitiske handlerum med militær aktivisme? En større udredning om beslutningsprocessen forud for Danmarks militære engagement i Kosovo, Afghanistan og Irak dokumenterer på baggrund af et omfattende arkivmateriale, at Danmarks militære engagement først og fremmest var styret af efterspørgslen fra USA (Mariager \& Wivel, 2019). Udredningen peger samtidig på, at begrundelserne for at imødekomme USA's efterspørgsel efter militære bidrag 
varierede mellem de tre konflikter. I Kosovo handlede det om at sikre, at NATO fortsatte som en stærk militær alliance med et aktivt amerikansk engagement, mens det i Afghanistan handlede om solidaritet med USA efter 9/11 og i Irak var udtryk for regeringens, særligt statsminister Anders Fogh Rasmussens, enighed i den amerikanske præsident George W. Bushs ønske om at udbrede demokrati og menneskerettigheder i Mellemøsten, med militærmagt om nødvendigt.

Viljen og evnen til at imødekomme den amerikanske efterspørgsel efter militært engagement er således en væsentlig betingelse for udviklingen af Danmarks militære aktivisme. ${ }^{2}$ Men hvordan forklarer vi denne vilje og evne? Litteraturen om dansk udenrigspolitisk aktivisme peger på national sikkerhed, international status og strategisk kultur som væsentlige brikker til en forståelse.

\section{Sikkerhed}

Den første hypotese er, at Danmark har imødekommet efterspørgslen fra USA af nationale sikkerhedshensyn. USA er NATO-landenes sikkerhedsgarant, og som påpeget ovenfor var Danmarks beslutning om NATO-medlemskab båret af netop nødvendigheden af en militær sikkerhedsgaranti, som man ikke fandt andre steder. NATO-medlemskabet udgjorde gennem den kolde krig en forsvarspolitisk hjørnesten i dansk udenrigspolitik og blev efter den kolde krigs afslutning både et middel til at fastholde det amerikanske engagement i europæisk sikkerhed og en platform for dansk samarbejde med udvalgte allierede i forskellige konstellationer (Ringsmose \& Rynning, 2017). Sovjetunionens kollaps og Kinas stigende magt formindsker det amerikanske incitament til at fortsætte med at betale for forsvaret af de stabile og rige europæiske lande, og forsikringspræmien for et fortsat amerikanske engagement i europæisk sikkerhed er derfor blevet forhøjet. Danmark og andre europæiske lande må derfor betale med militære bidrag til USA-ledede operationer i Mellemøsten og andre dele af verden (Mearsheimer, 2010).

Hypotesen kan også tage udgangspunkt i en bredere forståelse af sikkerhed. Danmark og andre europæiske landes tilslutning til den amerikanske koalition af villige i forbindelse med invasionen af Irak i 2003 er således blevet tolket som 'blød balancering' af franske visioner om et Europa, der er strategisk uafhængigt af USA (Paul, 2018, s. 110-115). Et amerikansk engagement i Europa er således ikke blot en garant for militær sikkerhed, men også for det lille atlantiske Danmarks mulighed for at balancere de europæiske stormagter. Bandwagoning med USA er balancering af Tyskland og Frankrig. Endelig kan dette tætte militære parløb med USA tolkes som svaret på et ontologisk sikkerhedsproblem. Den kolde krigs afslutning betød et farvel til den nordiske model som en effektiv identitetsmarkør i dansk udenrigspolitik. Den tredje vej mellem Øst og Vest gav ikke mening i en verden, hvor Øst var kollapset, og Vest havde vundet. De danske beslutningstagere søgte på den baggrund at placere

\footnotetext{
${ }^{2}$ Der synes her at være en interessant parallel til Norge, se Jakobsen, Ringsmose og Saxi (2018).
} 


\section{Anders Wivel}

Danmark som et aktivt og indflydelsessøgende europæisk land, men da de danske vælgere i 1992 stemte nej til Maastricht-traktaten, og Danmark efterfølgende valgte at fortsætte EU-medlemskabet med et forbehold overfor den fælles forsvarspolitik, blev det samarbejdet med USA i militærpolitikken, der gav Danmark mulighed for at videreføre rollen som landet, der aktivt søger at skabe en verden med respekt for demokrati og menneskerettigheder - en videreførelse af de nordiske idealer, men nu med militær magt (Wivel \& Crandall, 2019). Den øgede anvendelse af militære midler kombineret med en mere pragmatisk tilgang til spørgsmålet om, hvorvidt et direkte FN-mandat burde være en betingelse for dansk militært engagement, rummede dog samtidig en fare for at underminere de selvsamme idealer om fredelig konfliktløsning og styrkelse af det internationale samfund.

\section{Status}

På grund af deres begrænsede materielle kapabiliteter er små stater afhængige af international status (de Carvalho \& Neumann, 2015, s. 1). De har ikke militære muskler eller økonomisk tyngde som stormagterne, men hvis de demonstrerer deres nytte for disse magter og det internationale samfund, kan de øge sandsynligheden for, at de kan få adgang til information og støtte (Breitenbauch, 2015, s. 28). Dette gør små lande som Danmark særligt følsomme overfor krav og forventninger fra alliancepartnere, og de er derfor typisk imødekommende overfor de større landes krav og ivrige efter at udvikle niche-kapabiliteter, der gør dem i stand til at leve op til kravene (Jakobsen \& Rynning, 2019, s. 73). Troppebidrag er i den forbindelse et robust og synligt instrument til at signalere tilslutning til stormagtens dagsorden til gengæld for status (Græger, 2015). Danmarks deltagelse i militære operationer på Balkan, i Afghanistan, i Irak og i Libyen forklares på den baggrund med et dansk ønske om synlighed og anerkendelse i Washington, ofte med en forventning om, at denne kan veksles til sikkerhed, efterretninger og indflydelse (Jakobsen, Ringsmose \& Saxi, 2018; Pedersen, 2018).

\section{Strategisk kultur}

En tredje klynge af hypoteser fokuserer på Danmarks strategiske kultur. ${ }^{3} 1864$ resulterede $i$ en grundlæggende skepsis mod anvendelsen af militære midler og fastholdt den sikkerhedspolitiske debat i en konflikt mellem fredssag og forsvarssag. Det nye sikkerhedspolitiske miljø efter den kolde krig gav et større udenrigspolitisk handlerum og gav mulighed for, at begge sider af debatten kunne spejle sig i en udenrigspolitisk aktivisme, der stræbte efter at bidrage til et stærkt internationalt samfund, men ofte med militære midler (Rasmussen, 2005; Wivel, 2005), selv om implementeringen ikke altid afspejlede idealerne. Samtidig tillagde den dominerende tolkning

\footnotetext{
${ }^{3}$ For en diskussion af strategisk kultur i kontekst af forståelsen af de nordiske småstater, se Neumann og Heikka (2005).
} 
ansvaret for nederlaget i 1864 en uansvarlig og afkoblet politisk elite. Den kollektive lære - den dominerende diskurs - blev derfor, at udenrigspolitikken fremadrettet skulle tjene befolkningen pragmatisk og ikke igen sætte den nationale sikkerhed og selvstændighed på spil. Det betyder ikke, at værdipolitikken er fraværende, men ligesom Danmark i 1920'erne og 1930'erne arbejdede for frihandel og afspænding i skyggen af den tyske overmagt, og man fra 1960'erne under svensk lederskab søgte at fremme lighed og afspænding i skyggen af den kolde krig, så forfølges klassiske nordiske værdier som demokrati og menneskerettigheder nu indenfor rammerne af den amerikanske verdensorden. Værdier er udgangspunktet for dansk udenrigspolitik, men de fremmes i respekt for den nationale sikkerhed og de herskende magtforhold (Wivel, 2014). I de konkrete beslutninger om dansk militært engagement er denne strategiske kultur afsæt for et stærkt policy-fællesskab, hvor en begrænset kreds af aktører med særlig interesse og fælles forståelse for sikkerhedspolitikken har udviklet en konsensusbåret og kontinuerlig praksis for både beslutningsprocedure og politikkens indhold (Jakobsen, 2019).

Konkurrerende hypoteser, eklektisk puslespil eller samlet model?

De tre klynger af forklaringer kan anskues som konkurrerende hypoteser. De er imidlertid svære at teste - både på grund af begrænset kildeadgang, og fordi de snarere end testbare antagelser formulerer komplekse, historisk betingede klynger af beslægtede forklaringer. Alternativt kan de forstås som brikker i et puslespil, der tilsammen udgør en eklektisk forklaring på Danmarks militære aktivisme. Endelig kan de formuleres som elementer i en "udbudsmodel" for dansk militær aktivisme, hvor sikkerhed, status og strategisk kultur er tæt sammenvævet (Figur 1).

USA afgørende for

dansk sikkerhed
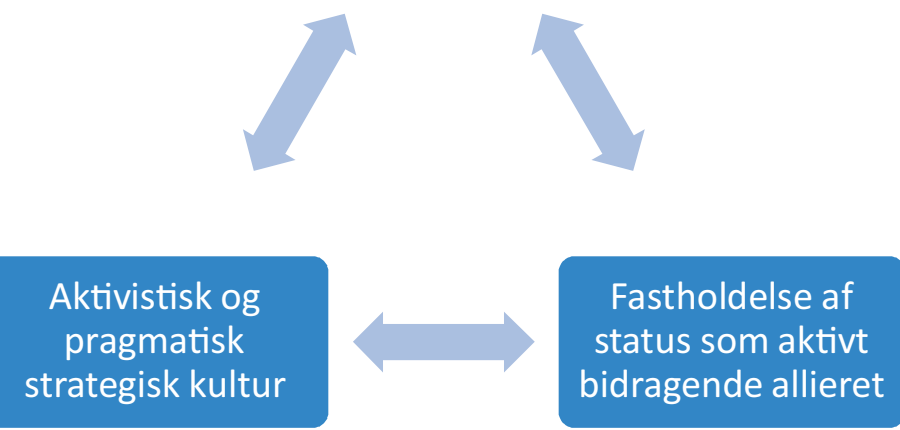

Figur 1 Danmarks udbud af militær aktivisme 
USA's afgørende betydning for dansk sikkerhed er udgangspunktet for den danske vilje til aktivt at fastholde en status som bidragende og konstruktiv allieret gennem deltagelse $\mathrm{i}$ internationale operationer. Men denne deltagelse er også medvirkende til at binde Danmark endnu tættere til USA, politisk og militært, gennem udviklinger af fælles praksisser og beslutninger om indkøb af materiel. Fastholdelse af status understøttes af en aktivistisk og pragmatisk strategisk kultur, der finder sit udtryk i et stærkt policy-fællesskab. Det policy-fællesskab træffer beslutninger om militær aktivisme med henblik på at sikre det amerikanske engagement, hvilket samtidig er med til at fastholde fokus på USA som den eneste mulighed for militær sikkerhed.

\section{Fremtiden}

Med udgangspunkt i modellen vil vi forvente, at Danmarks militære aktivisme er robust. Sikkerhedsgaranti, international status og strategisk kultur er tæt sammenvævede og gensidigt konstituerende. Den nuværende regering har som tidligere regeringer understreget USA's fortsatte betydning for Danmarks nationale sikkerhed, og bidrag til internationale operationer er fortsat et centralt element i dansk udenrigsog sikkerhedspolitik.

Indenfor disse rammer bør tre udviklinger dog fremhæves. For det første øges forsvarsbudgettet fra ca. 1,2 procent af BNP i 2018 til ca. 1,5 procent i 2023. Dette følger efter 2016-beslutningen om at bestille 29 nye F35 jagerfly. Forøgelsen er resultat af et amerikansk pres på Danmark og andre europæiske allierede. Danmarks militære aktivisme har hidtil været baseret på output-legitimitet: viljen til at bidrage til internationale operationer skulle veksles til status og sikkerhed. Washington har klart signaleret, at allierede i fremtiden i lige så høj grad vil blive vurderet på inputlegitimitet: forsvarsbudgettets størrelse og indkøb af materiel er afgørende for at blive betragtet som en god allieret. For det andet fokuserer dansk militær aktivisme i dag i højere grad på nærområdet end for få år siden. Dette er en konsekvens af en mere offensiv russisk udenrigspolitik, men i lige så høj grad en konsekvens af amerikanske forventninger til Danmarks rolle i Østersøområdet. Forventningen er nu, at Danmark skal kunne bidrage både ude i verden og i nærområdet. Endelig ses der en tendens til, at Danmark i højere grad diversificerer sit militære engagement, eksempelvis gennem samarbejde med Frankrig og deltagelse i European Intervention Initiative. Også denne tendens er drevet af USA, om end incitamentet her har været usikkerhed om USA's fremtidige rolle i Europa.

\section{Om forfatterne}

Anders Wivel er Professor (mso) ved Institut for Statskundskab, Københavns Universitet. Han er forfatter til en lang række artikler i danske og internationale tidsskrifter samt forfatter og redaktør af en række bøger senest Handbook on the Politics of 
Small States (Edward Elgar, 2020, medredaktør Godfrey Baldacchino) og International Institutions and Power Politics: Bridging the Divide (Georgetown University Press, 2019, medredaktør T.V. Paul). Fra 2017 til 2019 var han viceforskningsleder ved den uvildige udredning af det historiske forløb i forbindelse med Danmarks militære engagement i Kosovo, Afghanistan og Irak, krigsudredning.ku.dk.

\section{Referencer}

Albrechtsen, E., Frandsen, K. E. \& Lind, G. (2006). Konger og krige 700-1648. København: Gyldendal.

Breitenbauch, H. Ø. (2015). Uendelig krig?: Danmark, samtenkning og stabilisering af globale konflikter. København: Djøf Forlag.

de Carvalho, B. \& Neumann, I. B. (Reds) (2015). Small state status seeking: Norway's quest for international standing. London: Routledge.

Forsvarsministeriet (2020). Internationale Operationer. Hentet 15. april 2020 fra https://www.fmn.dk/temaer/ operationer/Pages/international-indsats.aspx

Glenthøj, R. (2018). 1864 før, nu og i fremtiden. Fortællinger i nyere og ældre dansk 1864-historiografi. Historisk Tidsskrift, 117(2), 566-598.

Græger, N. (2015). From 'forces for good' to 'forces for status'? I B. de Carvalho \& I. B. Neumann (Red.), Small state status seeking: Norway's quest for international standing (s. 86-107). London: Routledge.

Heurlin, B. (2007). Forsvar og sikkerhed i Norden: Ligheder og forskelle hos de nordiske lande. I B. Heurlin (Red.), Nationen eller Verden? De nordiske landes forsvar $i$ dag (s. 15-70). København: Jurist- og Økonomforbundets Forlag.

Holbraad, C. (1991). Danish neutrality: A study in the foreign policy of a small state. Oxford: Oxford University Press.

Jakobsen, P. V. (2015). Danmarks militære aktivisme fortsætter med eller uden USA. Politik, 18(4), 5-13.

Jakobsen, P. V. (2019). Policy-fællesskaber, standard-og krisestyringsprocedurer: det oversete institutionelle grundlag for den brede opbakning til Danmarks aktivistiske udenrigspolitik. Politica, 51(2), 139-167.

Jakobsen, P.V. \& Rynning, S. (2019). Denmark: Happy to fight, will travel. International Affairs, 95(4), 877-895.

Jakobsen, P. V., Ringsmose, J. \& Saxi, H. L. (2018). Prestige-seeking small states: Danish and Norwegian military contributions to US-led operations. European fournal of International Security, 3(2), 256-277.

Mariager, R. \& Wivel, A. (2019). Hvorfor gik Danmark $i$ krig? Uvildig udredning af baggrunden for Danmarks militcere engagement $i$ Kosovo, Afghanistan og Irak. København: Rosendahls.

Mearsheimer, J. J. (2010). Why is Europe peaceful today? European Political Science, 9(3), 387-397.

Mouritzen, H. (2007). Denmark's super Atlanticism. Fournal of Transatlantic Studies, 5(2), 155-167.

Neumann, I. B., \& Heikka, H. (2005). Grand strategy, strategic culture, practice: The social roots of Nordic defence. Cooperation and Conflict, 40(1), 5-23.

Paul, T. V. (2018). Restraining great powers: Soft balancing from empires to the global era. New Haven: Yale University Press.

Pedersen, R. B. (2018). Bandwagon for status: Changing patterns in the Nordic states status-seeking strategies? International Peacekeeping, 25(2), 217-241.

Pedersen, R. B. \& Ringsmose, J. (2017). Aktivisme i dansk udenrigspolitik: Norden, FN, NATO og EU. Politica, 49(4), 339-357.

Petersen, N. (2005). Danmark som international aktør 705-2005. Politica, 37(1), 44-59.

Petersen, N. (2006). Europaisk og globalt engagement, 1973-2003. København: Gyldendal.

Rasmussen, M. V. (2005). 'What's the use of it?': Danish strategic culture and the utility of armed force. Cooperation and Conflict, 40(1), 67-89.

Ringsmose, J. (2009). Paying for protection: Denmark's military expenditure during the Cold War. Cooperation and Conflict, 44(1), 73-97.

Ringsmose, J. \& Rynning, S. (2008). The impeccable ally? Denmark, NATO, and the uncertain future of top tier membership. I Hvidt, N. \& Mouritzen, H. (Red.), Danish foreign policy yearbook 2008 (s. 55-84).

Ringsmose, J. \& Rynning, S. (2017). Rutsjebane: udsving og udfordringer i Danmarks NATO-aktivisme. Politica, 49(4), 401-425.

SIPRI (2019). SIPRI military expenditure database: Data for all countries 1949-2018 (excel spreadsheet). Hentet 16. april $2020 \mathrm{fra} \mathrm{https://www.sipri.org/databases/milex}$ 
Villaume, P. (1995). Allieret med forbehold. Danmark, NATO og den kolde krig. En studie i dansk sikkerhedspolitik 1949-1961. København: Eirene.

Wivel, A. (2005). Between paradise and power: Denmark's transatlantic dilemma. Security Dialogue, 36(3), 417-421.

Wivel, A. (2014). Still living in the shadow of 1864? Danish foreign policy doctrines and the origins of Denmark's pragmatic activism. I H. Mouritzen \& N. Hvidt (Red.), Danish foreign policy yearbook 2014 (s. 109-139). København: DIIS.

Wivel, A. \& Crandall, M. (2019). Punching above their weight, but why? Explaining Denmark and Estonia in the transatlantic relationship. Fournal of Transatlantic Studies, 17(3), 392-419.

\section{Abstract in English \\ Constant Activism in a War with No End: \\ Security, Status and Strategic Culture in Danish Foreign Policy}

Danish foreign policy is militarily activist. Danish military activism is characterized by very different types of engagements and deployments regarding the number of troops and their legal mandate, political aims, institutional frameworks and geographical focus. The continuing Danish will to actively maintain its status as a contributing and constructive ally through participation in international military operations is driven by a perception of the United States as crucial to Denmark's national security and supported by an activist and pragmatic strategic culture. For these reasons, Danish military activism is robust, despite indications of change in financing, geographical focus and choice of partners.

Keywords: Danish foreign policy $\bullet$ activism $\bullet$ status $\bullet$ strategic culture $\bullet$ United States 